\title{
Escherichia coli 0157:H7 strains harbor at least three distinct sequence types of Shiga toxin 2a-converting phages
}

Shuang Yin ${ }^{1}$, Brigida Rusconi ${ }^{3}$, Fatemeh Sanjar ${ }^{3}$, Kakolie Goswami ${ }^{1}$, Lingzi Xiaoli ${ }^{1}$, Mark Eppinger $^{3}$ and Edward G. Dudley ${ }^{1,2,4^{*}}$

\begin{abstract}
Background: Shiga toxin-producing Escherichia coli O157:H7 is a foodborne pathogen that causes severe human diseases including hemolytic uremic syndrome (HUS). The virulence factor that mediates HUS, Shiga toxin (Stx), is encoded within the genome of a lambdoid prophage. Although draft sequences are publicly available for a large number of E. coli O157:H7 strains, the high sequence similarity of stx-converting bacteriophages with other lambdoid prophages poses challenges to accurately assess the organization and plasticity among stx-converting phages due to assembly difficulties.
\end{abstract}

Methods: To further explore genome plasticity of stx-converting prophages, we enriched phage DNA from 45 ciprofloxacin-induced cultures for subsequent 454 pyrosequencing to facilitate assembly of the complete phage genomes. In total, 22 stx2a-converting phage genomes were closed.

Results: Comparison of the genomes distinguished nine distinct phage sequence types (PSTs) delineated by variation in obtained sequences, such as single nucleotide polymorphisms (SNPs) and insertion sequence element prevalence and location. These nine PSTs formed three distinct clusters, designated as PST1, PST2 and PST3. The PST2 cluster, identified in two clade 8 strains, was related to stx2a-converting phages previously identified in nonO157 Shiga-toxin producing E. coli (STEC) strains associated with a high incidence of HUS. The PST1 cluster contained phages related to those from E. coli O157:H7 strain Sakai (lineage I, clade 1), and PST3 contained a single phage that was distinct from the rest but most related to the phage from E. coli O157:H7 strain EC4115 (lineage I/II, clade 8). Five strains carried identical stx2a-converting phages (PST1-1) integrated at the same chromosomal locus, but these strains produced different levels of Stx2.

Conclusion: The stx2a-converting phages of $\mathrm{E}$. coli O157:H7 can be categorized into at least three phage types. Diversification within a phage type is mainly driven by IS629 and by a small number of SNPs. Polymorphisms between phage genomes may help explain differences in Stx2a production between strains, however our data indicates that genes encoded external to the phage affect toxin production as well.

Keywords: Escherichia coli O157:H7, Shiga toxin, Bacteriophage, Genomics

\footnotetext{
* Correspondence: egd100@psu.edu

'Department of Food Science, The Pennsylvania State University, University Park, PA 16802, USA

${ }^{2}$ Center of Molecular Immunology and Infectious Disease, The Pennsylvania

State University, University Park, PA 16802, USA

Full list of author information is available at the end of the article
} 


\section{Background}

Shiga toxin-producing Escherichia coli (STEC) O157:H7 is a food- and waterborne human pathogen that causes diarrhea, hemorrhagic colitis $(\mathrm{HC})$, or in more severe cases hemolytic uremic syndrome (HUS) [1, 2]. Cattle are the primary reservoir of this pathogen and may be asymptomatically colonized [3]. Due to the serious disease and its low-infectious dose [4], E. coli $\mathrm{O} 157: \mathrm{H} 7$ is considered an adulterant in non-intact raw beef products in the United States. Shiga toxin (Stx) is one of the major virulence factors involved in E. coli O157:H7 pathogenesis [5]; based on immunoreactivity, toxins are classified as either Stx1 or Stx2 [6]. DNA sequence diversity further divides Stx2 into 7 allelic types (Stx2a through Stx2g) [7] with Stx2a and Stx2c most frequently associated with HUS $[8,9]$. During the stepwise evolution of E. coli $\mathrm{O} 157: \mathrm{H} 7$ from a common $E$. coli $\mathrm{O} 55: \mathrm{H} 7$ ancestor, genes encoding Stx1 and Stx2 were acquired horizontally by phage transduction [10]. In this established model, the st $x 2$-converting phage was acquired before the antigenic shift from O55 to O157, followed by stx1-converting phage acquisition. Follow-up studies refined this model $[11,12]$ and most recently, Lacher et al. [13] proposed a model taking into consideration acquisition and loss of stx1-, stx2a-, and stx2c-converting phage, and additional mutations that define E. coli O157:H7 sublineages. Genetic characterization together with clinical data has identified that two groups, designated clade 6 and clade 8 , are more commonly associated with severe disease than are isolates from other clades $[14,15]$.

The lambdoid stx-converting phages are temperate, exhibiting both lytic and lysogenic life cycles [16]. The lysogen-lytic switch is directed by several regulatory proteins including $c I, c I I, c I I I, c r o, \mathrm{~N}$, and $\mathrm{Q}$, the latter of which activates transcription from the late promoter, $p_{R^{\prime}}$. The genes encoding Stx 2 are positioned downstream of $p_{R^{\prime}}$ [17], and DNA damaging agents that activate lytic replication also increase toxin production [18]. Previous genomic analyses $[19,20]$ demonstrated that DNA sequence variation between stx2-converting phages occurs particularly within the regulatory regions, leading to the hypothesis that differences in the kinetics and abundance of prophage induction may be responsible for the variations in Stx2 production observed between different $E$. coli O157:H7 strains [21, 22]. This is supported by the observation that the $E$. coli $\mathrm{O} 157: \mathrm{H7} Q$ allele designated $\mathrm{Q}_{933}$ is a marker of high Stx2a producing strains [23], although this has not been seen in other isolate collections [24]. Other factors impacting toxin production include the presence of insertion sequences (IS) [24-26] within the phage genomes, and $c I$ repressors encoded within other prophage [27].

In previous publications we characterized $52 \mathrm{E}$. coli O157:H7 isolates from patients in Pennsylvania [28] and sequenced the genome of three isolates [29]. While the whole-genome sequence (WGS) data provided valuable information concerning strain diversity, the stx-converting phage genomes, critical for understanding toxin production, could not be fully assembled. Factors contributing to this include the short read technology used, and the high sequence identity with other lambdoid phages; e.g. 13 out of 18 prophages in E. coli O157:H7 Sakai are classified as lambdoid [30]. The objectives of the present work were to isolate and sequence $s t \times 2 a$-converting phages from a diverse set of $E$. coli $\mathrm{O} 157: \mathrm{H} 7$ strains, and to compare these phage genomes to those previously sequenced; the identification of identical phage within different $E$. coli $\mathrm{O} 157: \mathrm{H} 7$ hosts also allowed us to test whether factors encoded outside of the phage genome impact Stx2 production.

\section{Results}

\section{Phage genome assemblies}

To enrich phage DNA (phDNA), E. coli O157:H7 strains were induced by ciprofloxacin and total phDNA was isolated. For 22 of the 45 strains, sufficient dsDNA ( $\geq 200 \mathrm{ng}$ ) was obtained for 454 sequencing, and assembly resulted in complete stx $2 a$-converting phage genomes ranging in size from 61,292 to 65,334 bp (Table 1, Additional file 1: Table S1). In addition, two $15,957 \mathrm{bp}$ phage genomes unrelated to stx2a-converting phage and inserted at $y i c C$, yielded enough read coverage for complete phage assembly.

\section{Twenty-two stx2a-converting phage genomes form three genetic clusters}

Predicted phage proteomes were compared with Large Scale Blast Score Ratio (LS-BSR) [31]. Applying hierarchical average linkage clustering algorithm, which is part of $\mathrm{MeV}$ v.4.8 [32], on this proteomic matrix (Pearson Correlation) [33] identified three distinct phage clusters, designated as Phage Sequence type 1 (PST1), PST2 and PST3 (Fig. 1). These three clusters were also apparent within a whole genome alignment (Additional file 2: Figure S1). The 19 genomes classified as PST1 were further divided into six subtypes (PST1-1 to PST1-6) by assessing IS629 copy number and insertion sites (Fig. 2a). PST1-1 contained 13 phage genomes that each have IS629 inserted at the same position (nucleotides 24,350-25,659), splitting a predicted phage protein into two predicted proteins (as an example, those with protein_id AKI86024 and AKI86027 in the PA4 phage GenBank entry, KP682372). This insertion sequence is located downstream of the stx2 gene. Genome sequences of the $62 \mathrm{~kb}$ PST1-1 phage differed at most by five SNPs, and these SNP level differences were observed within the predicted $\mathrm{O}_{\mathrm{R} 2}$ operator, portal protein, tail fiber, and several hypothetical proteins (Additional file 3: Table S2). All PST1-1 isolates carry the stx2a-converting prophage found in the prototypical strain E. coli O157:H7 Sakai 
Table 1 Genome size, genomic insertion site, IS629 copy number, and host strain(s) for the nine Phage Sequence Types (PSTs) defined in this study

\begin{tabular}{lllll}
\hline PST & Genome Size $(\mathrm{bp})$ & Insertion site & IS629 copy number & Host Strain(s) \\
\hline $1-1$ & 62708 & wrbA & 1 & PA4, PA5, PA11, PA16, PA18, PA21, PA29, PA30, PA32, PA33, PA42, PA44, PA50 \\
$1-2$ & 61388 & $w r b A$ & 0 & PA12, PA51 \\
$1-3$ & 64021 & $w r b A$ & 2 & PA27 \\
$1-4$ & 64021 & $w r b A$ & 2 & PA36 \\
$1-5$ & 65334 & $w r b A$ & 3 & PA45 \\
$1-6$ & 65334 & wrbA & 3 & PA52 \\
$2-1$ & 63569 & tRNA(argm) & 1 & PA2 \\
$2-2$ & 63584 & tRNA(argW & 1 & PA8 \\
$3-1$ & 61292 & tRNA(argW & 2 & PA28 \\
\hline
\end{tabular}

[30]. The two phages in PST1-2 were $100 \%$ identical on the nucleotide level, and PSTs $1-3,-4,-5$, and -6 each represent single phage found in strains PA27, PA36, PA45, and PA52, respectively.

We found that all PST1 cluster phages inserted within $w r b A$, which encodes a TrpR binding protein, while both the PST2 and PST3 cluster phages were inserted within the tRNA $\arg W$ (Table 1). The int sequences were identical for the PST2 and PST3 cluster phages. However, these were clearly of different evolutionary origin or have substantially diverged from int encoded within PST1 cluster phage, as neither the DNA nor the deduced amino acid sequences could be aligned using BLAST [34]. A correlation between int sequences and insertion site has been noted before [35].

IS629 insertion and position is a main driver of genetic variation observed within PST1 and PST2 clusters

Genomes from the PST1 phage cluster ranged in size from 61,388 to 65,334 bp (Table 1 ). IS629 copy numbers, ranging from 0 (PST1-2) to 3 (PST1-5 and PST1$6)$, accounted for most of this difference. The insertion site and orientation of IS629 varied as well (Fig. 2a and Additional file 4: Table S3). For instance, for PSTs 1-3 and 1-6, the transposon inserted at position 25,663, interrupting the gene for a putative DNA-binding protein Roi. IS629 also inserted at position 28,390 in PST1-5, interrupting a putative lysozyme, and at position 2456 in PST2-1, interrupting a putative adenine DNA methyltransferase. In PST2-2, the insertion was found at position 31,540 within an intergenic region (Fig. $2 b$ and Additional file 4: Table S3).

\section{Phage early regulatory and replication regions differed among the three clusters}

We next performed a global alignment of representative phage genomes from PST1, PST2, and PST3 (Fig. 3). Most differences were observed within regions predicted to encode the phages' early regulatory and replication genes.
For example, $c I$ (annotated as protein_id AKI86003 in the PST1-1 phage from PA4, AKI85932 in the PST2-1 phage from PA2, and AKI86748 in the PST3-1 phage from PA28) and cro (protein_id AKI86003 in the PA4 phage, AKI85933 in PA2, and AKI86749 in PA28) only shared 9.8-49.8\% amino acid sequence identity over the full gene length among the three clusters (Additional file 5: Table S4). Homologs that were distantly related by amino acid identity could still be identified by their shared patterns defined in the Clusters of Orthologous Groups database [36]. Predicted operator sequences [37, 38] were identified between $c I$ and cro $\left(\mathrm{O}_{\mathrm{R} 1}, \mathrm{O}_{\mathrm{R} 2}\right.$, and $\left.\mathrm{O}_{\mathrm{R} 3}\right)$ and between $c I$ and $N\left(\mathrm{O}_{\mathrm{L} 1}, \mathrm{O}_{\mathrm{L} 2}\right.$, and $\left.\mathrm{O}_{\mathrm{L} 3}\right)$ in genomes of the PST1 and PST3 cluster (Additional file 6: Table S5). We could not identify putative operator sequences or homologs to the early regulatory genes $c I I I$ and $c I I$ in the PST2 cluster, but instead a type II restriction/modification enzyme system $(b s u B I)$ was found at the corresponding region.

The sequence divergence within predicted early regulatory and replication genes is contrasted by the conservation of predicted late and structural genes. For instance, one of the late genes encoding a putative lysozyme (protein_id AKI86033 in PA4, AKI85950 in PA2, and AKI86778 in PA28), shared 95-98 \% amino acid sequence identity over the full gene length among the 3 clusters (Additional file 5: Table S4).

\section{The PST2 cluster is more closely related to the stx2a-converting phage of E. coli 0104:H4 2011C-3493 rather than to PST1 and PST3}

Phage genomes were extracted from 10 closed bacterial genomes deposited in GenBank (Additional file 7: Table S6), and we compared these to the nine PSTs established in this study and to seven other representative stx $2 a$-converting phages from the E. coli O157:H7 lineage and non-O157 serotypes. We identified sequence fragments present in at least 3 of the 24 genomes using Panseq [39], and their distribution, presence or absence, 


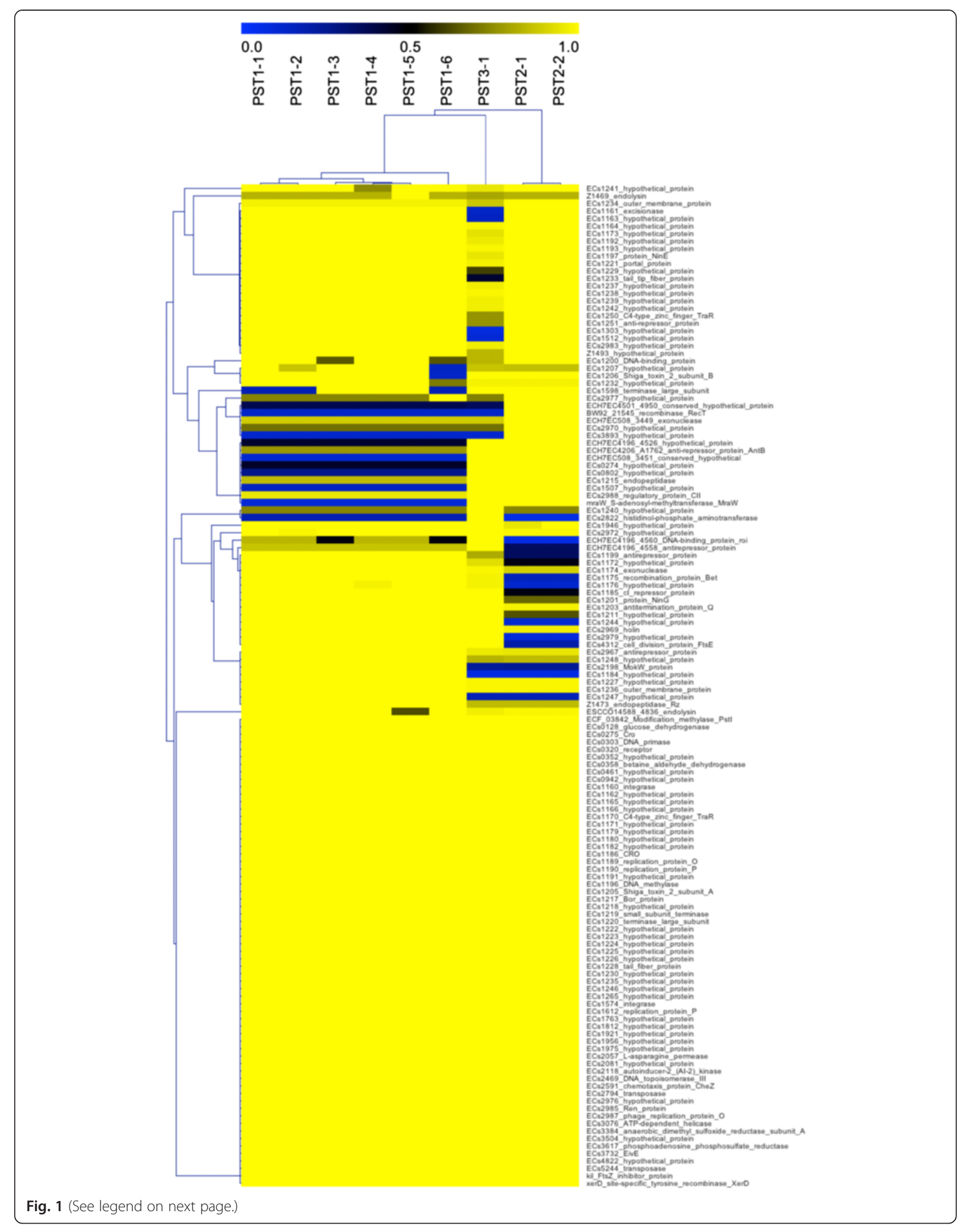


(See figure on previous page.)

Fig. 1 Nine phage sequence types (PSTs) form three clusters when compared at the proteomic level. De novo gene prediction with prodigal was used to have consistent ORF prediction prior to tblastn analysis. Resulting LS-BSR values were clustered by average linkage hierarchical clustering resulting in three distinct main phage clusters (PST-1, PST-2, PST-3). Five proteins were highly conserved in PST2, 4 in PST3 and 6 in PST1, and almost $50 \%$ of proteins are conserved in all phages. The LS-BSR for each ORF identifies unique (Blue $=0)$, divergent $(B l a c k=0.5)$ and common proteins (Yellow = 1.0) [87]

in each phage genome was used to infer a neighborjoining tree [40] using SplitsTree 4 (Fig. 4). The PSTs within a cluster were located on the same node and this PST2 cluster was more related to stx2- phages from highly virulent non-O157 strains, such as E. coli O104:H4 2011C-3493 [41], O103:H2 [42], and O103:H25 [43] when compared to PSTs 1 or 3.

BLAST comparisons [34] were performed between representative PSTs from each of the 3 clusters and the nearest neighbor from Fig. 4. PST1-1 and the EDL933 stx2a- phage [19], differed mainly within the predicted phages' early regulatory and replication region (Fig. 5a, Additional file 8: Table S7). For PST2-1 and the phage in strain E. coli O104:H4 2011C-3493, phage regulatory and replication regions showed a higher degree of similarity (Fig. 5b, Additional file 8: Table S7). Noteworthy, the
bsuBI restriction/modification system in PST2-1 is also present in the O104:H4 2011C-3493 phage genome [41]. Most differences between the two phages were found within regions encoding ORFs with no assigned functions. The most evident difference between PST3-1 and the EC4115 phage was within a region encoding genes for $N$, $c I$, and cro (Fig. 5c, 78).

\section{E. coli 0157: $\mathrm{H} 7$ host genome affects Stx2 production}

Our analyses identified for the first time strains of $E$. coli O157:H7 (PA4, PA18, PA30, PA33, and PA44) carrying stx2a-converting phages (PST1-1) that were $100 \%$ identical on the phDNA level and had the same insertion site (wrbA). These strains also carry an stx1-converting phage [28]. This provided us with the unique opportunity to use non-manipulated strains to ask whether factors

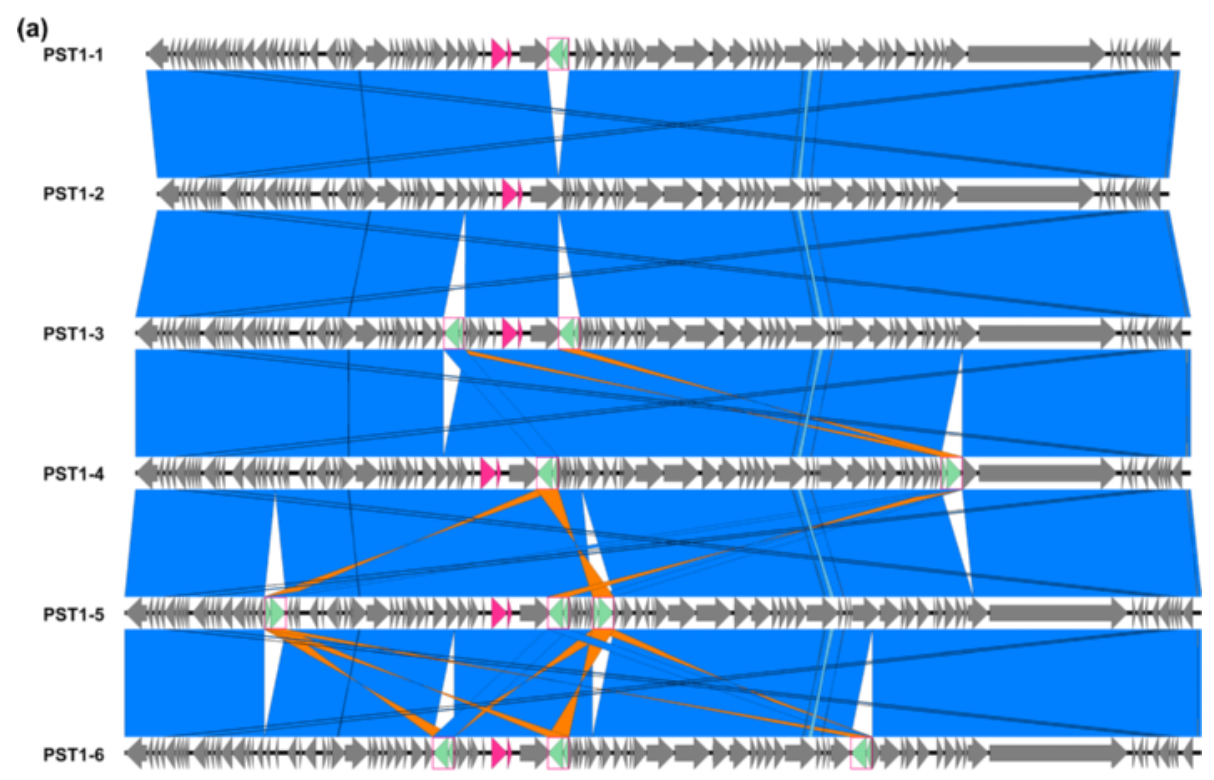

(b)

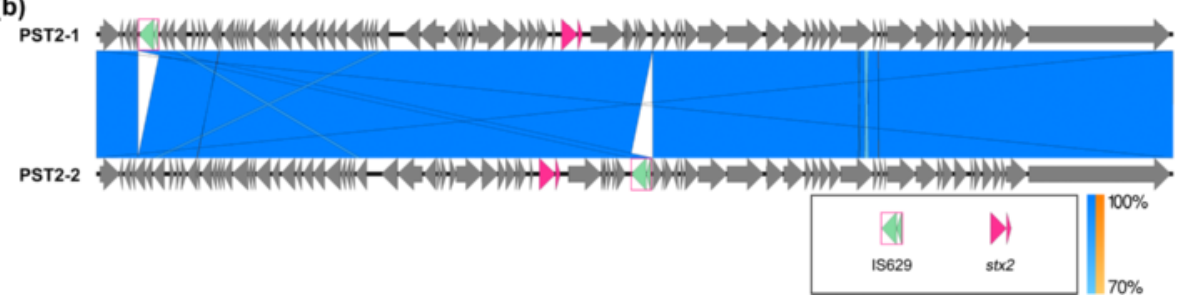

Fig. 2 IS629 is responsible for most diversity observed within (a) PST1 and (b) PST2 clusters. BLAST comparisons of phage genomes were visualized using Easyfig [77]. Blue shaded regions connect homologous sequences and orange shaded regions connect reverse complemented homologous sequences. Arrows represent ORFs. Dark pink and green arrows designate the location of st×2a and IS629, respectively 

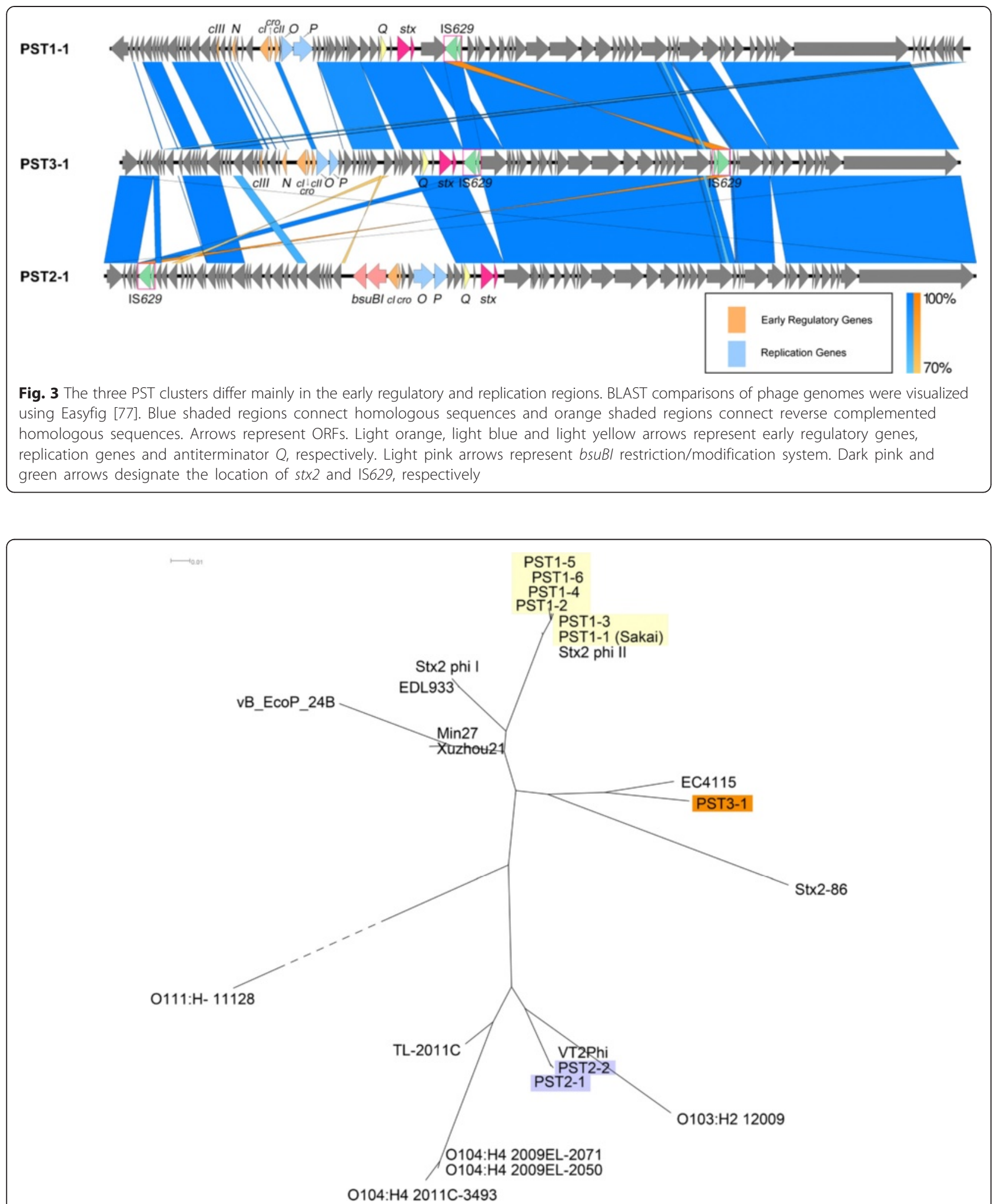

Fig. 4 Phages of PST2 are related to those from strains associated with high HUS rates. Host strain names or phage names are indicated. Phage genomes were cut into 500 bp fragments. The "Core genome" was defined as fragments present in $>2$ phage genomes at > $85 \%$ identity using Panseq [39]. The presence or absence of core genome fragments in each phage genome was used for clustering. Uncorrected P-distance was used to build a neighbor-joining tree using SplitsTree 4 [80]. PST1, PST2, and PST3 clusters are highlighted by yellow, light purple and orange shading, respectively 


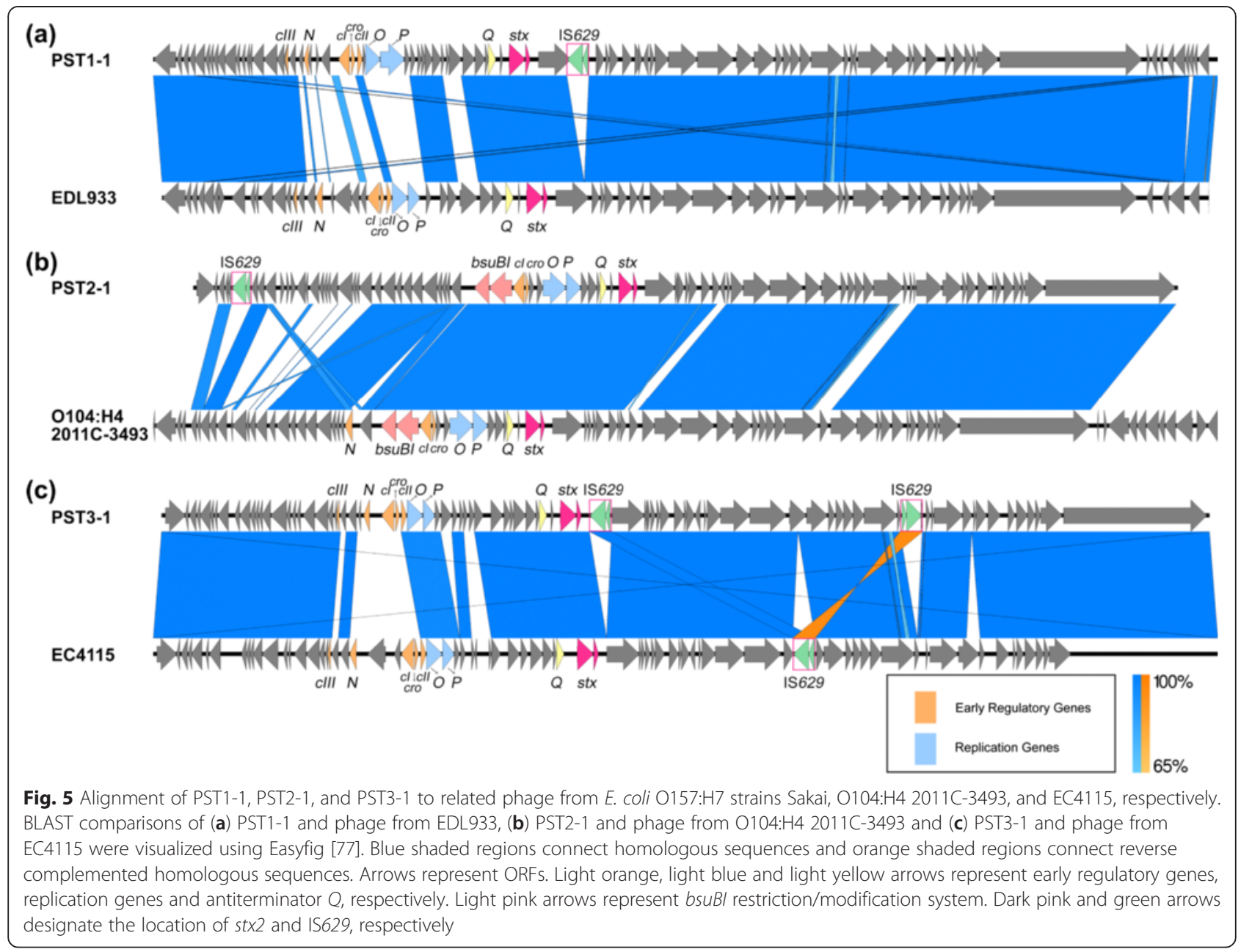

apart from the stx2a-converting phage genome impact toxin production. To first investigate the genetic relatedness of the host strains, we established a phylogenomic framework derived from whole genome alignments of shared regions, excluding prophage, for all $45 \mathrm{E}$. coli O157:H7 genomes [44, 45] (Fig. 6). Strains PA4, PA18, PA30, PA33 and PA44 are phylogenetically positioned on separate branches indicating that, as expected, no two chromosomes genomes were identical. Next, we measured the Stx2a levels and stx2a expression after ciprofloxacin phage-induction (Fig. 7a). The lowest Stx2a producer was PA4, at approximately $1 \mathrm{ng} / \mu \mathrm{g}$ of protein, and the highest producer was PA44, at approximately $5 \mathrm{ng} / \mu \mathrm{g}$ of protein. PA18 produced $3.2 \mathrm{ng} / \mu \mathrm{g}$, which was significantly different from the previous two strains, while toxin production from strains PA30 $(4.4 \mathrm{ng} / \mu \mathrm{g})$ and PA33 $(4.6 \mathrm{ng} / \mu \mathrm{g})$ was only different from PA4. Surprisingly, stx2a transcript levels were similar for all strains except for PA18, which was greater than 10-fold above that measured with PA4, PA30, PA33, or PA44 (Fig. 7b). This observed disconnect indicates that qPCR does not always reflect the level of Stx 2 secreted by $E$. coli $\mathrm{O} 157: \mathrm{H} 7$.

\section{Discussion}

The progression and severity of HUS is thought to correlate with the amount of Stx 2 produced by $E$. coli O157:H7 [46]. E. coli O157:H7 strains vary by their toxin production potential and this likely results in different virulence potentials $[22,47]$. Molecular methods previously grouped E. coli $\mathrm{O} 157: \mathrm{H} 7$ strains into three lineages and nine clades [14, 48, 49]. Lineage I has been more frequently observed with isolates of human origin (at least in the United States) than were lineage I/II or lineage II isolates $[48,49]$. This is presumably due, in part, to higher levels of Stx2 produced by lineage I isolates compared to other lineages [22]. As production of Stx2 is directly linked to phage replication [50], it is not surprising that we were most successful in isolating phDNA for sequencing from lineage I isolates. We only obtained sufficient DNA from 3 out of 12 clade 8 (lineage I/II) strains, which some reports suggested are 


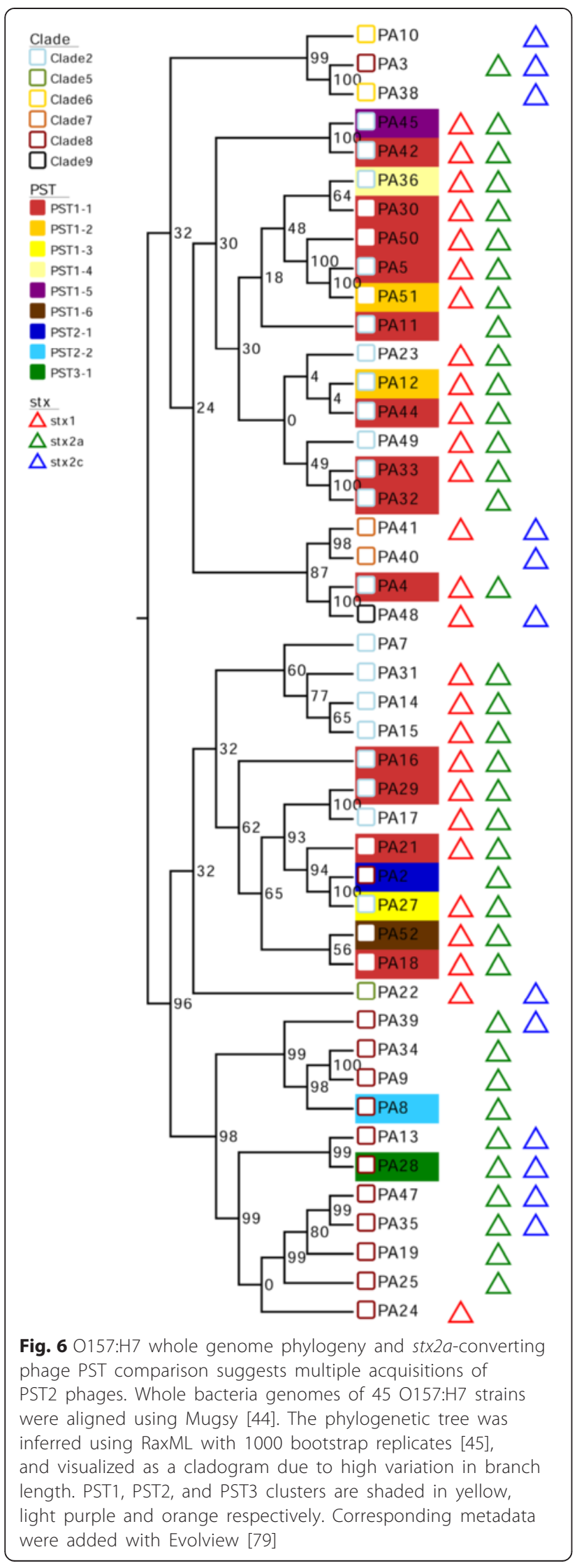

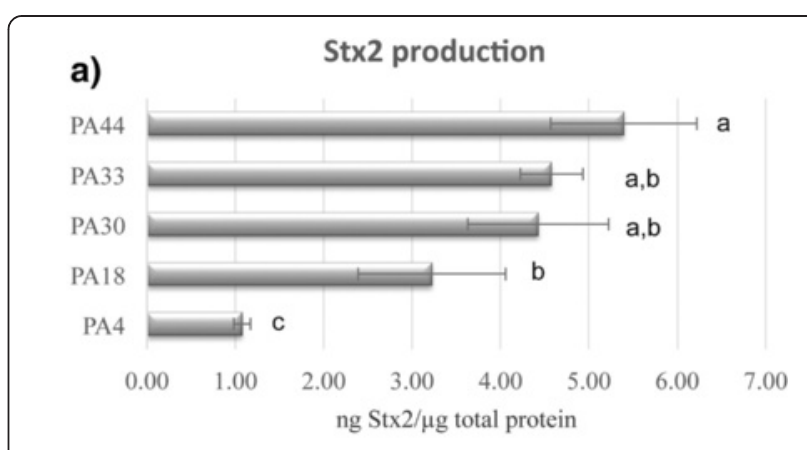

b)

stx2a expression

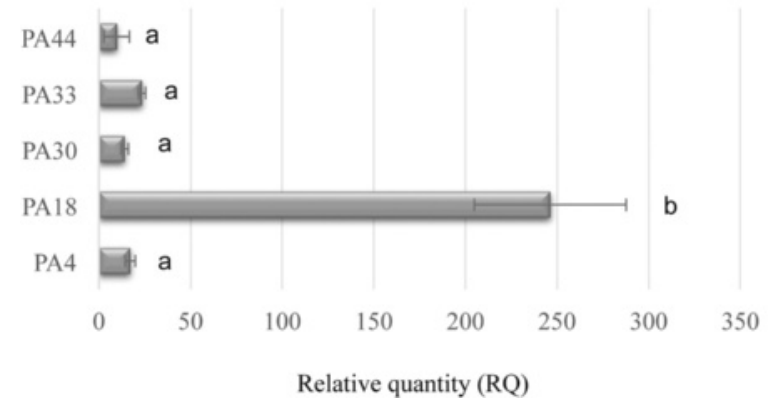

Fig. 7 Host factors modulate stx2a expression levels. (a) Whole genomes of 14 O157:H7 strains with PST1-1 were aligned using Mugsy [44] and the phylogenetic tree was inferred using RaxML [45] with 100 bootstrap replicates and visualized using Figtree [88]. (b) Stx2 production was quantified by ELISA $2 \mathrm{~h}$ after ciprofloxacin induction. Bars labeled with different letters were significantly different $(P<0.05)$

high Stx2 producers [51], although another study [22] suggested Stx2 levels are at least one-log less than lineage I isolates. We were also unable to isolate sufficient phDNA from lineage II (clade 7) isolates (PA40, PA41) or from a clade 9 isolate (PA48); these groups of isolates are also typically low toxin producers [22]. While other temperate phages in E. coli O157:H7 are inducible [52], we only obtained sufficient DNA to close genomes for two others isolated from PA2 and PA8 that are related to a phage designated $\mathrm{Sp} 7$ in strain Sakai [30]. In contrast, the coverage for all stx2a-converting phages sequenced here was $117-573$-fold. This data is consistent with the observations that most prophage in the E. coli $\mathrm{O} 157: \mathrm{H} 7$ genome are defective [52] and that the genome copy number of stx $2 a$-converting phage upon mitomycin $\mathrm{C}$ induction is at least two orders of magnitude higher than for other prophages.

Previous studies suggested that genetic polymorphisms between stx $2 a$-converting phage genomes could impact levels of toxin production [20,23, 53]. Our study identified eight new genotypes of stx2a-converting phage, almost doubling the number of complete phage genomes 
varieties deposited. We observed that one major driving force of phage genome diversity is in IS629 copy number and location variations. This is in accordance with previous studies that identified multiple copies of IS629, especially in the prophage, prophage-like and plasmid regions $[24,25,54,55]$. This provides us with several testable hypotheses for how polymorphisms in the phage genome may impact toxin levels. For example, stx $2 a$ expression and subsequent release of toxin from the bacteria requires induction of the lytic cycle. Noteworthy, we observed a disruption of a putative roi in PST1-3 and PST1-6, which encodes a DNA-binding protein that inhibits the activation of the lytic cycle [56]. Therefore, we speculate that the specific IS629 insertion in PST1-3 and PST1-6 may increase toxin production in strains carrying these phage sequence types. Once Stx2 is produced, efficient release of the toxin requires lysis of the bacteria. In PST1-5, the gene encoding a putative lysozyme was disrupted which could reduce the amount of toxin released. Inactivation of adenine DNA methyltransferase genes such as that observed in PST2-1 may additionally affect toxin production through de-repressing the lytic cycle [57].

The other major source of phage genome diversity, as noted before [19], was located within early regulatory regions. The diversity of this region is driven by homologous recombination between different lambdoid prophages $[30,58,59]$. Previous studies have also suggested that polymorphisms in early regulatory genes could lead to differential $s t x$ expression $[23,37,38]$. For example, the cooperative binding of $\mathrm{CI}$ dimers to operator sites designated $\mathrm{O}_{L}$ and $\mathrm{O}_{R}$ maintains the phage in its lysogenic state through repressing transcription from the $\mathrm{P}_{\mathrm{L}}$ and $P_{R}$ promoters, respectively. The copy number of each operator site can vary, for example $E$. coli $\mathrm{O} 157: \mathrm{H} 7$ strain EDL933 has two $\mathrm{O}_{\mathrm{L}}$ sites surrounding $\mathrm{P}_{\mathrm{L}}$ that are designated $\mathrm{O}_{\mathrm{L} 1}$ and $\mathrm{O}_{\mathrm{L} 2}$, while the strain Sakai also has an $\mathrm{O}_{\mathrm{L} 3}$ [37]. Four hours post antibiotic phage-induction, Stx2a production is greater for EDL933 than Sakai [60], and one reasonable hypothesis could be that this is caused by decreased repression at $\mathrm{O}_{\mathrm{L}}$ [37, 38]. As with the PST1 phage from Sakai, our PST3 phage also had three identifiable $\mathrm{O}_{L}$ and $\mathrm{O}_{R}$ sites, however, we were unable to identify operator sequences or some early regulatory genes in the PST2 cluster phages. Whether one or more of these differences are responsible for the reduced quantities of toxin produced by strain PA2 compared to Sakai and EDL933 [60] remains to be determined.

Both PST2 and PST3 phages are found within clade 8 of $E$. coli $\mathrm{O} 157: \mathrm{H7}$, which is a subgroup associated with high incidence of hospitalization and HUS [14, 15]. We found that PST2 phages were highly similar to the Stx2a phage of E. coli O104:H4 2011C-3493, a Stx2a-expressing enteroaggregative $E$. coli (EAEC) that was responsible for a severe outbreak in Germany in 2011 [41]. A related phage designated TL-2011C (Fig. 4) is found within the genome of an E. coli O103:H25 strain that caused a small outbreak in Norway [43] that again was characterized by a high HUS rate. Future research should investigate whether these phages are indicators of high Stx2a producing strains.

Diversity within the phage genome undoubtedly plays an important role in toxin production, however other factors encoded within the host may also influence the phage lifestyle [61]. Our assembly of phage genomes identified several E. coli O157:H7 strains carrying identical stx $2 a$-converting prophages that were integrated at the same genomic site. Importantly, all of these strains also contain stx1-converting phage, which are known to decrease Stx 2 production in E. coli O157:H7 strains carrying both phages [27]. Thus, by using wild-type clinical isolates that have been minimally passaged since isolation, we could test the hypothesis that genes external to the phage impact toxin production. Indeed, we observed a greater than five-fold variation in Stx2 production between PA4 and PA44, demonstrating that future studies investigating the mechanism(s) behind differences in Stx expression must take both phage and chromosomal host background into consideration. We also noted some discordance between toxin protein and transcript levels (Fig. 7), which is similar to observations with E. coli O157:H7 strain TW08612 [51]. This suggests that caution must be taken when assessing potential virulence of $E$. coli O157:H7 by qPCR alone. The identification of highly similar phage was also observed with stx2-converting phage from E. coli O104:H4 isolates [62], highlighting a remarkable stability contrasted to the mosaic structure that also exists between phage as reported here and elsewhere [63].

Although a single acquisition of the stx2a-converting phage was suggested in the well-established stepwise evolution model from $\mathrm{O} 55: \mathrm{H} 7$ to $\mathrm{O} 157: \mathrm{H} 7$ [10, 11, 13], prophage regions are also known as hotspots of horizontal gene transfer. Laing et al. [40] used both complete genome and WGS to compare stx-converting phage phylogeny with their host bacterial phylogeny and found that the two phylogenies generally agree with each other. However, the phage genomes extracted from WGS were not necessarily fully assembled and this may have influenced the accuracy of this analysis [40]. Unlike most whole genome shotgun sequencing studies, which do not allow for precise assembly of stx-converting phage regions, our study accomplished this by enriching for and sequencing phDNA after removal of bacterial genomic DNA. Our data suggest that PST1 phages in general evolved vertically along with the host. We did however observe that E. coli O157:H7 strains PA2 and PA8, both of which carry PST2 phages, occupy distinct nodes on the tree generated from 
whole genome alignments (Fig. 6). While it is possible that this demonstrates mobilization of the PST2 phages, our limited genomic data set is clearly insufficient to make any firm conclusions.

\section{Conclusion}

This study expands our knowledge of the genetic diversity within stx2a-converting phages, and suggests that both phage and bacterial sequences, as well as phage insertion sites modulate Stx2 production. Sequencing additional stx $2 a$-converting phages is justified, but should probably use other approaches as the strategy we took may bias results towards high phage producing strains. Next Generation Sequencing (NGS) long read technologies, such as PacBio, have been used by other investigators for accurate phage genome assemblies when other (related/homologous) phages are present as well [64]. As a larger number of complete genomes become available, a more comprehensive comparison to other Enterobacteria phage lambda will be possible that accounts for exchange of phage through genetic recombination, establishing whether the phage genotypes described could be considered distinct species. This study also serves as robust foundation for future work investigating whether the phage genome polymorphisms observed impact the virulence phenotype, particularly Stx2 production, both in pure culture and in combination with other members of the gut microbiota.

\section{Methods}

\section{Bacterial strains and culture media}

The 45 E. coli $\mathrm{O} 157: \mathrm{H} 7$ isolates used in this study were obtained from the Pennsylvania Department of Health and were originally characterized by Hartzell et al. (2011) [28]. All isolates were stored at $-80{ }^{\circ} \mathrm{C}$ in $10 \%$ glycerol and grown in Luria-Bertani (LB) [65] at $37^{\circ} \mathrm{C}$.

\section{Phage DNA isolation and sequencing}

Phage DNA (phDNA) was isolated as previously described [66]. Briefly, each of the 45 isolates (Additional file 1: Table S1) was grown overnight in LB at $37{ }^{\circ} \mathrm{C}$ with constant shaking. To induce the phages' lytic cycle, each overnight culture was diluted in LB supplemented with $45 \mathrm{ng} / \mathrm{ml}$ ciprofloxacin to an optical density of 0.05 at $600 \mathrm{~nm}\left(\mathrm{OD}_{600}\right)$ and incubated for $8 \mathrm{~h}$ at $37^{\circ} \mathrm{C}$ with shaking. Supernatants were collected after centrifugation $\left(4000 \times g, 10 \mathrm{~min}, 4{ }^{\circ} \mathrm{C}\right)$ and filtration $(0.2-\mu \mathrm{m}$ cellulose acetate filter; VWR, Philadelphia, PA) and treated with 0.6 Unit/ml DNase I (Promega, Madison, WI) and $1.8 \mu \mathrm{g} / \mathrm{ml}$ RNase (Promega, Madison, WI) at $37{ }^{\circ} \mathrm{C}$ for $1 \mathrm{~h}$ to digest gDNA and RNA. The treated supernatants were incubated o/n with $10 \%$ (wt/vol) polyethylene glycol 8000 (Promega, Madison, WI) and $1 \mathrm{M} \mathrm{NaCl}$ at $4{ }^{\circ} \mathrm{C}$. After centrifugation $\left(5000 \times g, 2 \mathrm{~h}, 4{ }^{\circ} \mathrm{C}\right)$, each pellet was resuspended in $\mathrm{SM}$ buffer $\left(0.58 \% \mathrm{NaCl}, 0.2 \% \mathrm{MgSO}_{4} \cdot 7 \mathrm{H}_{2} \mathrm{O}, 1 \mathrm{M}\right.$ Tris-Cl [pH 7.5], and $0.01 \%$ gelatin) and treated with $50 \mu \mathrm{g} / \mathrm{ml}$ proteinase K (EMD, Darmstadt, Germany) at $65{ }^{\circ} \mathrm{C}$ for $1 \mathrm{~h}$ to digest the phage capsid protein and release phDNA. A phenol-chloroform $(1: 1 \mathrm{vol} / \mathrm{vol})$ extraction was performed to remove protein and the Clean and Concentrator kit (Zymo Research, Irvine, CA) was used to further purify and concentrate phDNA. The double-strand DNA (dsDNA) was quantified using the dsDNA BR assay kit (Qubit, Grand Island, NY). Purified phDNA (>200 ng) was sequenced using a Roche GS 454 FLX+ system (454 Life Science, Branford, CT) at the Penn State Genome Core Facility. Sequencing of gDNA was performed by the University of Maryland Institute for Genome Sciences on the Illumina HiSeq 2000.

\section{Phage genome assembly}

The phDNA reads for each of the 22 isolates were assembled de novo using SeqMan NGen (DNASTAR, Madison, WI). The average sequencing depth ranged from 117 to 573. For each isolate, BLAST analysis of contigs (>1000 bp) was performed against the nonredundant nucleotide database in GenBank to identify the best matching phage genome to use as a reference for scaffold building. Reference genomes were VT2Phi (accession HQ424691) [40, 67] for strains PA2 and PA8, E. coli O157:H7 EC4115 (accession CP001164) [53] for strain PA28, and Sakai (accession BA000007) [30] for the remaining phage. Gaps were closed by manual curation, and the draft genome was corrected for homopolymers using Illumina gDNA reads previously generated from the E. coli $\mathrm{O} 157: \mathrm{H} 7$ host strain (Additional file 1: Table S1). Finally, PCR followed by DNA sequencing was used to validate the location of the IS elements within the phages.

\section{Phage genome annotation}

Phage genomes were auto-annotated using RAST [68] and PHAST [69]. The GenBank files generated by RAST were then manually curated in Artemis [70] using the following principles: (i) prophage integration sites and tRNA genes carried by the phage were identified by PHAST, if present; (ii) open reading frames (ORFs) predicted to encode proteins of 39-94 amino acids, when present on the opposite DNA strand from and overlapping a predicted operon, were deleted if no known function had been ascribed to that ORF; (iii) if RAST and PHAST identified a different start codon for the same ORF, the Glimmer-based [71] prediction of PHAST was followed; (iv) ORFs identified by RAST but not PHAST were kept if one of the following was observed: a BLAST match was identified with a gene of known function, a Pfam motif was identified [72], Psortb [73] identified at 
least one secondary structure feature, or Fugue [74] returned a match with confidence interval greater than $99 \%$; (v) for ORFs identified by PHAST but not RAST, guideline iv was followed except the Fugue confidence interval was reduced to greater than $95 \%$. A few exceptions to these rules exist: (a) in PA2, PA8 and PA28, the 3' end of the integrase overlaps with the 3 ' end of the downstream ORF, however both ORFs were annotated; (b) in PA45, ORF49 and 50 are predicted to be convergently transcribed and overlap at their stop codons. We kept these ORFs since guideline iv and $v$ supported each.

\section{Comparative genome analysis}

Illumina HighSeq reads were mapped to assemblies with CLC Genomics Workbench 7.04 (CLC Bio) to assess quality and coverage of predicted SNPs. All SNPs had a coverage above $100 \times$ and Phred scores of 64. Phage genome alignments were generated with progressive Mauve [75] and visualized with Geneious R7.1.7. [76]. Comparisons of gene and protein sequences were performed using ClustalW packaged in MegAlign (DNASTAR Inc, Madison, WI) to identify SNPs and calculate sequence percent identities. BLASTN alignments of phage genomes were visualized using EasyFig [34, 77].

\section{Phylogenetic trees}

Multiple sequence alignments were performed via Mugsy for whole genome alignments of both E. coli chromosomal and phage genomes [44]. The alignment was then imported into Galaxy [78] to convert the MAF alignment file into a fasta file containing a single entry per strain. The maximum likelihood phylogenetic trees were inferred using RAxML V7.2 [45], with the following parameters: rapid bootstrapping and GTRGAMMA with 100 and 1000 bootstraps for chromosomes and phages, respectively. Trees and strain-associated metadata were visualized with Evolview [79].

The phage genome tree that includes phages from GenBank was generated using the method and parameters described by Laing et al. [40]. Panseq [39] was used to cut phage genomes into $500 \mathrm{bp}$ fragments. The "core genome" was defined by combining fragments present in $\geq 3$ phage genomes at $>85 \%$ identity. Other parameters were 'nucB' = '200', 'nucC' = '50', 'nucD' = '0.12', 'nucG' = '100' and 'nucL' = '11'. The presence or absence of core genome fragments in each phage genome was used for clustering. Uncorrected P-distance was used to build a neighbor-joining tree by SplitsTree 4 [80].

\section{BLAST Score Ratio Analysis}

The phage proteome for each of the 9 phages sequence types were predicted using the Prodigal [81] gene prediction software. The concatenated predicted ORFs were then de-replicated with Usearch [82] and run through comparative BLAST score ratio (BSR) analysis [31] using TBLASTN [34]. For each of the predicted proteins, a BLASTP raw score was obtained for the alignment against itself (REF_SCORE) and the most similar protein (QUE_SCORE) in each of the genomes. Dividing the QUE_SCORE obtained for each query genome protein by the REF_SCORE normalized these scores and constitutes the BLAST score ratio (BSR). Proteins with a normalized BSR of $<0.4$ were considered to be nonhomologous. A normalized BSR of 0.4 correspond to two proteins being $30 \%$ identical over their entire length [31, 83].

\section{Stx2 gene expression and toxin production}

Stx2 gene expression and toxin production was quantified using reverse transcription-qPCR and ELISA, respectively. Briefly, overnight LB cultures of each strain were diluted to an $\mathrm{OD}_{600}$ of 0.05 with fresh LB media supplemented with $40 \mathrm{ng} / \mathrm{mL}$ of ciprofloxacin [84] and incubated for $2 \mathrm{~h}$ at $37{ }^{\circ} \mathrm{C}$ with shaking. For reverse transcription-qPCR, total RNA was isolated using the Ambion PureLink mini kit (Life Technologies, Grand Island, NY). The RNA quantity and quality was assessed at absorbance of $260 \mathrm{~nm}$ using UV-spectrophotometer. RNA was treated with amplification grade DNase I (Invitrogen, Grand Island, NY) and used for cDNA synthesis with the Masterscript kit (5 PRIME, Gaithersburg, MD). The primer pairs for stx2a (5'-TCCCGTCAACCTTCACTGTA-3' and 5'-GCGGTTTTATTTGCATTAGC-3, target subunit B gene) [85] and tufA (5'-TGGTTGATGACGAAGAGCTG3 ' and 5'- GCTCTGGTTCCGGAATGTAA-3') [86] were used in conjunction with Go-Taq ${ }^{\circ}$ qCR Master Mix (Promega, Madison, WI) and MicroAmp Fast optical real-time 96-well PCR plates (Applied Biosystems, Grand Island, NY) in an ABI StepOne PLUS Real-Time PCR system (Applied Biosystems, Grand Island, NY). Dissociation curves were analyzed for all reactions to verify single peaks/products. Expression levels of stx $2 a$ were normalized against tufA using ABI StepOne PLUS System SDS software (Applied Biosystems, Grand Island, NY) and shown in relative quantity (RQ). Three biological replication were conducted for each strain. For ELISA analysis, pre-warmed polymyxin $B(6 \mathrm{mg} / \mathrm{mL})$ was added to the induced culture and incubate for $10 \mathrm{~min}$ at $37^{\circ} \mathrm{C}$ to lyse all the bacteria. Supernatants were collected after centrifugation $\left(4000 \times \mathrm{g}, 10 \mathrm{~min}, 25^{\circ} \mathrm{C}\right)$ and diluted to measurable concentrations. The 96 well polystyrene microtiter strip plates (Thermo Scientific, Waltham, MA) coated with $2.5 \mu \mathrm{g}$ of ceramide trihexoside (Matreya Biosciences, Pleasant Gap, PA) were used for ELISA. After coating, the plates were incubated $\mathrm{o} / \mathrm{n}$ at $4{ }^{\circ} \mathrm{C}$ with blocking buffer $(4 \%$ bovine serum albumin in $0.01 \mathrm{M}$ phosphate buffer saline with $0.05 \%$ Tween 20$)$. Samples $(100 \mu \mathrm{l})$ were added to each well and incubated for $1 \mathrm{~h}$ at room temperature with 
shaking. After removing the samples, the wells were washed with PBS-Tween (PBST) buffer for five times. Mouse anti-Stx2 (Santa Cruz Biotech, Santa Cruz CA) $(1 \mu \mathrm{g} / \mathrm{ml}, 100 \mu \mathrm{l})$ was added to each well. Plates were incubated for $1 \mathrm{~h}$ at room temperature with shaking, followed by five PBST washes. Goat anti-mouse IgG peroxidase conjugated $(0.1 \mu \mathrm{g} / \mathrm{mL}, 100 \mu \mathrm{l})$ secondary antibody was added and incubated for $1 \mathrm{~h}$ at room temperature with shaking. After five PBST washes, $100 \mu \mathrm{l}$ of 1-Step Ultra TMB (3,3,5,5' tetramethylbenzidine) was added to each well, and the plates were incubated for $10 \mathrm{~min}$ at room temperature followed by the addition of an equal volume of stopping solution $\left(2 \mathrm{M} \mathrm{H}_{2} \mathrm{SO}_{4}\right)$. The $\mathrm{OD}$ at $450 \mathrm{~nm}$ was examined using a spectrophotometer. A standard curve was constructed for each plate and three technical repeats were performed for each sample. Total protein for each sample was measure using the Bradford assay. Three biological replicates were conducted for each strain. Data were analyzed using one-way analysis of variance (ANOVA) and Tukey's test by R Version 3.0.2.

\section{Additional files}

Additional file 1: Table S1. Information on Escherichia coli O157:H7 strains used in this study, and Genbank accession numbers for whole genome shotgun sequences and for completed phage genomes. (PDF 88 kb)

Additional file 2: Figure S1. Phage genomes were aligned with Mugsy and visualized in Geneious. Conserved regions compared to E. coli 0157:H7 strain PA4 are highlighted in gray. Mean pairwise identity over all columns represents $100 \%$ in dark green, 30-99\% in green-brown and below $30 \%$ in red. (PDF $84 \mathrm{~kb}$ )

Additional file 3: Table S2. SNPs observed within the PST1 cluster of phage. (PDF $59 \mathrm{~kb}$ )

Additional file 4: Table S3. Copy number and insertion site of IS629 elements in phage genomes sequenced in this study. (PDF $56 \mathrm{~kb}$ )

Additional file 5: Table S4. Sequence identity of selected genes encoded within the 3 PSTs defined in this study. (PDF $62 \mathrm{~kb}$ )

Additional file 6: Table S5. Putative operator sequences identified in PST1 and PST3 phage. (PDF $45 \mathrm{~kb}$ )

Additional file 7: Table S6. GenBank information and insertion site of previously sequenced st $\times 2$-converting phage used in this study [89-93]. (PDF $71 \mathrm{~kb}$ )

Additional file 8: Table S7. Sequence percent identity of regulatory genes and proteins, comparing each PST to the closest related previously sequenced phage. (PDF $59 \mathrm{~kb}$ )

\section{Competing interests}

The authors declare that they have no competing interests.

\section{Authors' contributions}

$S Y, K G$, and EGD designed the initial study. KG developed methods for large-scale preparation of phage DNA and submitted genomes for sequencing. SY performed genome assembly and bioinformatic analyses of the phage genomes. LX performed ELISA assays for Shiga toxin quantification. FS designed and performed qPCR assays used in this study. BR and ME performed whole genome analyses of bacterial strains and cluster analysis of phage genomes. SY, BR, FS, ME, and EGD wrote the manuscript.

Author's information

Not applicable.
Availability of data and materials

Not applicable.

\section{Acknowledgements}

We thank the Penn State Genomics Core Facility (University Park, PA) for generating phage DNA sequence information. We thank other members of the Dudley laboratory (Dr. Nikki Shariat, Michael DiMarzio) for their critical reading of drafts of this manuscript

\section{Funding}

This work was funded by USDA-NIFA grant 2010-65201-20619. The GSCID sequencing project was funded in part by federal funds from the National Institute of Allergy and Infectious Diseases, National Institutes of Health, Department of Health and Human Services, under contract number HHSN272200900009C. This work received support from the South Texas Center of Emerging Infectious Diseases (STCEID), Department of Biology and Computational System Biology Core at the University of Texas at San Antonio. This article is based upon work at the University of Texas at San Antonio (M.E.) supported by the Army Research Office of the Department of Defense under Contract No. W91 1NF-11-1-0136. B.R. is supported by the SNSF Early Postdoc Mobility P2LAP3-151770. F.S. is supported in part by a stipend from the South Texas Center for Emerging Infectious Diseases (STCEID).

\section{Author details}

'Department of Food Science, The Pennsylvania State University, University Park, PA 16802, USA. ${ }^{2}$ Center of Molecular Immunology and Infectious Disease, The Pennsylvania State University, University Park, PA 16802, USA ${ }^{3}$ Department of Biology and South Texas Center for Emerging Infectious Diseases, University of Texas at San Antonio, San Antonio, TX 78249, USA. ${ }^{4} 427$ Food Science Building, The Pennsylvania State University, University Park, PA 16802, USA.

Received: 9 June 2015 Accepted: 15 September 2015

Published online: 29 September 2015

\section{References}

1. Kaper JB, Nataro JP, Mobley HLT. Pathogenic Escherichia coli. Nat Rev Microbiol. 2004;2:123-40.

2. Gyles CL. Shiga toxin-producing Escherichia coli: an overview. J Anim Sci. 2007;85(13 Suppl):E45-62.

3. Borczyk AA, Karmali MA, Lior H, Duncan LM. Bovine reservoir for verotoxin-producing Escherichia coli O157:H7. Lancet. 1987;1:98.

4. Tilden Jr J, Young W, McNamara AM, Custer C, Boesel B, Lambert-Fair MA, et al. A new route of transmission for Escherichia coli: infection from dry fermented salami. Am J Public Heal. 1996;86:1142-5.

5. Melton-Celsa A, Mohawk K, Teel L, O'Brien AD. Pathogenesis of Shiga-toxin producing Escherichia coli. Curr Top Microbiol Immunol. 2012;357:67-103.

6. Strockbine NA, Marques LR, Newland JW, Smith HW, Holmes RK, O'Brien AD. Two toxin-converting phages from Escherichia coli O157:H7 strain 933 encode antigenically distinct toxins with similar biologic activities. Infect Immun. 1986;53:135-40.

7. Scheutz F, Teel LD, Beutin L, Piérard D, Buvens G, Karch H, et al. Multicenter evaluation of a sequence-based protocol for subtyping Shiga toxins and standardizing Stx nomenclature. J Clin Microbiol. 2012;50:2951-63.

8. Friedrich AW, Bielaszewska M, Zhang W-L, Pulz M, Kuczius T, Ammon $A$, et al. Escherichia coli harboring Shiga toxin 2 gene variants: frequency and association with clinical symptoms. J Infect Dis. 2002;185:74-84.

9. Persson S, Olsen KEP, Ethelberg S, Scheutz F. Subtyping method for Escherichia coli Shiga toxin (Verocytotoxin) 2 variants and correlations to clinical manifestations. J Clin Microbiol. 2007:45:2020-4.

10. Feng P, Lampel KA, Karch H, Whittam TS. Genotypic and phenotypic changes in the emergence of Escherichia coli 0157:H7. J Infect Dis. 1998;177:1750-3.

11. Leopold SR, Magrini V, Holt NJ, Shaikh N, Mardis ER, Cagno J, et al. A precise reconstruction of the emergence and constrained radiations of Escherichia coli 0157 portrayed by backbone concatenomic analysis. Proc Natl Acad Sci U S A. 2009:106:8713-8.

12. Leopold SR, Shaikh N, Tarr PI. Further evidence of constrained radiation in the evolution of pathogenic Escherichia coli O157:H7. Infect Genet Evol. 2010;10:1282-5. 
13. Lacher DW. The Evolutionary Model of Escherichia coli 0157:H7. In: Walk ST, Feng PCH, editors. Population Genetics of Bacteria: a Tribute to Thomas S. Whittam. 1st ed. Washington, DC: ASM Press; 2011. p. 227-39.

14. Manning SD, Motiwala AS, Springman AC, Qi W, Lacher DW, Ouellette LM, et al. Variation in virulence among clades of Escherichia coli 0157:H7 associated with disease outbreaks. Proc Natl Acad Sci U S A. 2008;105:4868-73.

15. lyoda S, Manning SD, Seto K, Kimata K, Isobe J, Etoh Y, et al. Phylogenetic clades 6 and 8 of enterohemorrhagic Escherichia coli 0157:H7 with particular stx subtypes are more frequently found in isolates from hemolytic uremic syndrome patients than from asymptomatic carriers. Open Forum Infect Dis. 2014;1:1-8.

16. Casjens SR, Hendrix RW. Bacteriophage lambda: Early pioneer and still relevant. Virology. 2015;1-21.

17. Wagner PL, Neely MN, Zhang X, Acheson DW, Waldor MK, Friedman DI. Role for a phage promoter in Shiga toxin 2 expression from a pathogenic Escherichia coli strain. J Bacteriol. 2001;183:2081-5.

18. Mühldorfer I, Hacker J, Keusch GT, Acheson DW, Tschäpe H, Kane AV, et al. Regulation of the Shiga-like toxin II operon in Escherichia coli. Infect Immun. 1996;64:495-502.

19. Miyamoto H, Nakai W, Yajima N, Fujibayashi A, Higuchi T, Sato K, et al. Sequence analysis of Stx2-converting phage VT2-Sa shows a great divergence in early regulation and replication regions. DNA Res. 1999;6:235-40.

20. Smith DL, Rooks DJ, Fogg PCM, Darby AC, Thomson NR, McCarthy AJ, et al. Comparative genomics of Shiga toxin encoding bacteriophages. BMC Genomics. 2012;13:311.

21. Ziebell K, Steele M, Zhang Y, Benson AK, Taboada EN, Laing CR, et al. Genotypic characterization and prevalence of virulence factors among Canadian Escherichia coli 0157:H7 strains. Appl Environ Microbiol. 2008;74:4314-23.

22. Zhang Y, Laing CR, Zhang Z, Hallewell J, You C, Ziebell K, et al. Lineage and host source are both correlated with levels of Shiga toxin 2 production by Escherichia coli 0157:H7 strains. Appl Environ Microbiol. 2010;76:474-82.

23. Lejeune JT, Abedon ST, Takemura K, Christie NP, Sreevatsan S. Human Escherichia coli 0157:H7 genetic marker in isolates of bovine origin. Emerg Infect Dis. 2004;10:1482-5.

24. Eppinger M, Mammel MK, Leclerc JE, Ravel J, Cebula TA. Genome signatures of Escherichia coli 0157:H7 isolates from the bovine host reservoir. Appl Environ Microbiol. 2011;77:2916-25.

25. Stanton E, Park D, Döpfer D, Ivanek R, Kaspar CW. Phylogenetic characterization of Escherichia coli 0157:H7 based on IS629 distribution and Shiga toxin genotype. Microbiology. 2014;160(Pt 3):502-13.

26. Park D, Stanton E, Ciezki K, Parrell D, Bozile M, Pike D, et al. Evolution of the Stx2-encoding prophage in persistent bovine Escherichia coli 0157:H7 strains. Appl Environ Microbiol. 2013;79:1563-72.

27. Serra-Moreno R, Jofre J, Muniesa M. The Cl repressors of Shiga toxin-converting prophages are involved in coinfection of Escherichia coli strains, which causes a down regulation in the production of Shiga toxin 2. J Bacteriol. 2008;190:4722-35.

28. Hartzell A, Chen C, Lewis C, Liu K, Reynolds S, Dudley EG. Escherichia coli 0157:H7 of genotype lineage-specific polymorphism assay 211111 and clade 8 are common clinical isolates within Pennsylvania. Foodborne Pathog Dis. 2011;8:763-8.

29. Eppinger M, Daugherty S, Agrawal S, Galens K, Sengamalay N, Sadzewicz L, et al. Whole-genome draft sequences of 26 enterohemorrhagic Escherichia coli 0157:H7 strains. Genome Announc. 2013;1, e0013412.

30. Hayashi T, Makino K, Ohnishi M, Kurokawa K, Ishii K, Yokoyama K, et al. Complete genome sequence of enterohemorrhagic Escherichia coli 0157:H7 and genomic comparison with a laboratory strain K-12. DNA Res. 2001;8:11-22.

31. Sahl JW, Caporaso JG, Rasko DA, Keim P. The large-scale blast score ratio (LS-BSR) pipeline: a method to rapidly compare genetic content between bacterial genomes. PeerJ. 2014;2, e332.

32. Saeed Al, Sharov V, White J, Li J, Liang W, Bhagabati N, et al. TM4: a free, open-source system for microarray data management and analysis. Biotechniques. 2003;34:374-8.

33. Eisen MB, Spellman PT, Brown PO, Botstein D. Cluster analysis and display of genome-wide expression patterns. Proc Natl Acad Sci U S A. 1998;95:14863-8.

34. Altschul SF, Gish W, Miller W, Myers EW, Lipman DJ. Basic local alignment search tool. J Mol Biol. 1990;215:403-10.

35. Steyert SR, Sahl JW, Fraser CM, Teel LD, Scheutz F, Rasko DA. Comparative genomics and stx phage characterization of LEE-negative Shiga toxin-producing Escherichia coli. Front Cell Infect Microbiol. 2012;2:133.
36. Tatusov R, Fedorova N, Jackson J, Jacobs A, Kiryutin B, Koonin EV, et al. The COG database: an updated version includes eukaryotes. BMC Bioinformatics. 2003;4:41.

37. Fattah KR, Mizutani S, Fattah FJ, Matsushiro A, Sugino Y. A comparative study of the immunity region of lambdoid phages including Shiga-toxin-converting phages: molecular basis for cross immunity. Genes Genet Syst. 2000;75:223-32.

38. Tyler JS, Mills MJ, Friedman DI. The operator and early promoter region of the Shiga toxin type 2-encoding bacteriophage $933 \mathrm{~W}$ and control of toxin expression. J Bacteriol. 2004;186:7670-9.

39. Laing CR, Buchanan C, Taboada EN, Zhang Y, Kropinski A, Villegas A, et al. Pan-genome sequence analysis using Panseq: an online tool for the rapid analysis of core and accessory genomic regions. BMC Bioinformatics. 2010;11:461.

40. Laing CR, Zhang Y, Gilmour MW, Allen V, Johnson R, Thomas JE, et al. A comparison of Shiga-toxin 2 bacteriophage from classical enterohemorrhagic Escherichia coli serotypes and the German E. coli 0104:H4 outbreak strain. PLoS One. 2012;7:e37362.

41. Ahmed SA, Awosika J, Baldwin C, Bishop-Lilly KA, Biswas B, Broomall S, et al. Genomic comparison of Escherichia coli 0104:H4 isolates from 2009 and 2011 reveals plasmid, and prophage heterogeneity, including Shiga toxin encoding phage st×2. PLOS One. 2012;7, e48228.

42. Ogura Y, Ooka T, Iguchi A, Toh H, Asadulghani M, Oshima K, et al. Comparative genomics reveal the mechanism of the parallel evolution of 0157 and non-O157 enterohemorrhagic Escherichia coli. Proc Natl Acad Sci U S A. 2009;106:17939-44.

43. L'Abée-Lund TM, Jørgensen HJ, O'Sullivan K, Bohlin J, Ligård G, Granum PE, et al. The highly virulent 2006 Norwegian EHEC 0103:H25 outbreak strain is related to the 2011 German O104:H4 outbreak strain. PLoS One. 2012;7, e31413.

44. Angiuoli SV, Salzberg SL. Mugsy: fast multiple alignment of closely related whole genomes. Bioinformatics. 2011;27:334-42.

45. Stamatakis A. RAxML version 8: a tool for phylogenetic analysis and post-analysis of large phylogenies. Bioinformatics. 2014;30:1312-3.

46. Nguyen $Y$, Sperandio V. Enterohemorrhagic E. coli (EHEC) pathogenesis. Front Cell Infect Microbiol. 2012;2:90.

47. Baker DR, Moxley RA, Steele MB, LeJeune JT, Christopher-Hennings J, Chen D-G, et al. Differences in virulence among Escherichia coli 0157:H7 strains isolated from humans during disease outbreaks and from healthy cattle. Appl Environ Microbiol. 2007;73:7338-46.

48. Kim J, Nietfeldt J, Benson AK. Octamer-based genome scanning distinguishes a unique subpopulation of Escherichia coli 0157:H7 strains in cattle. Proc Natl Acad Sci U S A. 1999;96:13288-93.

49. Yang Z, Kovar J, Kim J, Nietfeldt J, Smith DR, Moxley RA, et al. Identification of common subpopulations of non-sorbitol-fermenting, $\beta$-glucuronidase-negative Escherichia coli 0157:H7 from bovine production environments and human clinical samples. Appl Env Microbiol. 2004;70:6846-54.

50. Pacheco AR, Sperandio V. Shiga toxin in enterohemorrhagic E.coli: regulation and novel anti-virulence strategies. Front Cell Infect Microbiol. 2012;2(June):1-12.

51. Neupane M, Abu-Ali GS, Mitra A, Lacher DW, Manning SD, Riordan JT. Shiga toxin 2 overexpression in Escherichia coli O157:H7 strains associated with severe human disease. Microb Pathog. 2011;51:466-70.

52. Asadulghani M, Ogura $Y$, Ooka T, Itoh T, Sawaguchi A, Iguchi A, et al. The defective prophage pool of Escherichia coli 0157: prophage-prophage interactions potentiate horizontal transfer of virulence determinants. PLoS Pathog. 2009;5, e1000408.

53. Eppinger M, Mammel MK, Leclerc JE, Ravel J, Cebula TA. Genomic anatomy of Escherichia coli 0157:H7 outbreaks. Proc Natl Acad Sci U S A. 2011;108:20142-7.

54. Ooka T, Ogura Y, Asadulghani M, Ohnishi M, Nakayama K, Terajima J, et al. Inference of the impact of insertion sequence (IS) elements on bacterial genome diversification through analysis of small-size structural polymorphisms in Escherichia coli 0157 genomes. Genome Res. 2009:19:1809-16.

55. Yokoyama E, Hashimoto R, Etoh Y, Ichihara S, Horikawa K, Uchimura M. Biased distribution of IS629 among strains in different lineages of enterohemorrhagic Escherichia coli serovar O157. Infect Genet Evol. 2011;11:78-82

56. Clerget M, Boccard F. Phage HK022 Roi protein inhibits phage lytic growth in Escherichia coli integration host factor mutants. J Bacteriol. 1996;178:4077-83. 
57. Murphy KC, Ritchie JM, Waldor MK, Lobner-Olesen A, Marinus MG. Dam methyltransferase Is required for stable lysogeny of the Shiga toxin (Stx2)-encoding bacteriophage $933 \mathrm{~W}$ of enterohemorrhagic Escherichia coli 0157:H7. J Bacteriol. 2008;190:438-41.

58. Perna NT, Plunkett G, Burland V, Mau B, Glasner JD, Rose DJ, et al. Genome sequence of enterohaemorrhagic Escherichia coli O157:H7. Nature. 2001;409:529-33.

59. Ohnishi M, Kurokawa K, Hayashi T. Diversification of Escherichia coli genomes: are bacteriophages the major contributors? Trends Microbiol. 2001:9:481-5.

60. Goswami K, Chen C, Xiaoli L, Eaton KA, Dudley EG. Co-culturing Escherichia coli O157:H7 with a non-pathogenic E. coli strain increases toxin production and virulence in a germ-free mouse model. Infect Immun. 2015; [Epub ahead of print].

61. Friedman DI. Interaction between bacteriophage lambda and its Escherichia coli host. Curr Opin Genet Dev. 1992;2:727-38

62. Grande L, Michelacci V, Tozzoli R, Ranieri P, Maugliani A, Caprioli A, et al. Whole genome sequence comparison of verocytotoxin2-converting phages from enteroaggregative haemorrhagic Escherichia coli strains. BMC Genomics. 2014;15:574.

63. Johansen BK, Wasteson Y, Granum PE, Brynestad S. Mosaic structure of Shiga-toxin-2-encoding phages isolated from Escherichia coli 0157:H7 indicates frequent gene exchange between lambdoid phage genomes. Microbiology. 2001;147:1929-36.

64. Klumpp J, Fouts DE, Sozhamannan S. Next generation sequencing technologies and the changing landscape of phage genomics. Bacteriophage. 2012;2:190-9.

65. Bertani G. Studies on lysogenesis. I. The mode of phage liberation by lysogenic Escherichia coli. J Bacteriol. 1951;62:293-300.

66. Chen C, Lewis CR, Goswami K, Roberts EL, DebRoy C, Dudley EG. Identification and characterization of spontaneous deletions within the Sp11-Sp12 prophage region of Escherichia coli 0157:H7 Sakai. Appl Environ Microbiol. 2013;79:1934-41.

67. Brzuszkiewicz E, Thürmer A, Schuldes J, Leimbach A, Liesegang H, Meyer F-D, et al. Genome sequence analyses of two isolates from the recent Escherichia coli outbreak in Germany reveal the emergence of a new pathotype: Entero-Aggregative-Haemorrhagic Escherichia coli (EAHEC). Arch Microbiol. 2011;193:883-91.

68. Overbeek R, Olson R, Pusch GD, Olsen GJ, Davis JJ, Disz T, et al. The SEED and the Rapid Annotation of microbial genomes using Subsystems Technology (RAST). Nucleic Acids Res. 2014;42(Database issue):D206-14.

69. Zhou Y, Liang Y, Lynch KH, Dennis JJ, Wishart DS. PHAST: a fast phage search tool. Nucleic Acids Res. 2011;39(Web Server issue):W347-52.

70. Rutherford K, Parkhill J, Crook J, Horsnell T, Rice P, Rajandream MA, et al. Artemis: sequence visualization and annotation. Bioinformatics. 2000;16:944-5.

71. Salzberg SL, Delcher AL, Kasif S, White O. Microbial gene identification using interpolated Markov models. Nucleic Acids Res. 1998:26:544-8.

72. Finn RD, Bateman A, Clements J, Coggill P, Eberhardt RY, Eddy SR, et al. Pfam: the protein families database. Nucleic Acids Res. 2014;42(Database issue):D222-30.

73. Yu NY, Wagner JR, Laird MR, Melli G, Rey S, Lo R, et al. PSORTb 3.0: improved protein subcellular localization prediction with refined localization subcategories and predictive capabilities for all prokaryotes. Bioinformatics. 2010;26:1608-15.

74. Shi J, Blundell TL, Mizuguchi K. FUGUE: sequence-structure homology recognition using environment-specific substitution tables and structure-dependent gap penalties. J Mol Biol. 2001;310:243-57.

75. Darling AE, Mau B, Perna NT. Progressivemauve: Multiple genome alignment with gene gain, loss and rearrangement. PLoS One. 2010:5:e11147.

76. Kearse M, Moir R, Wilson A, Stones-Havas S, Cheung M, Sturrock S, et al. Geneious Basic: An integrated and extendable desktop software platform for the organization and analysis of sequence data. Bioinformatics. 2012;28:1647-9.

77. Sullivan MJ, Petty NK, Beatson SA. Easyfig: a genome comparison visualizer Bioinformatics. 2011:27:1009-10.

78. Goecks J, Nekrutenko A, Taylor J. Galaxy: a comprehensive approach for supporting accessible, reproducible, and transparent computational research in the life sciences. Genome Biol. 2010;11:R86.
79. Zhang H, Gao S, Lercher MJ, Hu S, Chen W-H. EvolView, an online tool for visualizing, annotating and managing phylogenetic trees. Nucleic Acids Res. 2012;40(Web Server issue):W569-72

80. Huson DH, Bryant D. Application of phylogenetic networks in evolutionary studies. Mol Biol Evol. 2006;23:254-67.

81. Hyatt D, Chen G-L, Locascio PF, Land ML, Larimer FW, Hauser LJ. Prodigal: prokaryotic gene recognition and translation initiation site identification. BMC Bioinformatics. 2010;11:119.

82. Edgar RC. Search and clustering orders of magnitude faster than BLAST. Bioinformatics. 2010;26:2460-1.

83. Rasko DA, Myers G, Ravel J. Visualization of comparative genomic analyses by BLAST score ratio. BMC Bioinformatics. 2005;6:2.

84. Zhang X, McDaniel AD, Wolf LE, Keusch GT, Waldor MK, Acheson DW Quinolone antibiotics induce Shiga toxin-encoding bacteriophages, toxin production, and death in mice. J Infect Dis. 2000;181:664-70.

85. Wang G, Clark CG, Rodgers FG. Detection in Escherichia coli of the genes encoding the major virulence factors, the genes defining the 0157:H7 serotype, and components of the type 2 Shiga toxin family by multiplex PCR. J Clin Microbiol. 2002:40:3613-9.

86. Gobert AP, Vareille M, Glasser A-L, Hindré T, de Sablet T, Martin C. Shiga toxin produced by enterohemorrhagic Escherichia coli inhibits PI3K/NF-kappaB signaling pathway in globotriaosylceramide-3-negative human intestinal epithelial cells. J Immunol. 2007;178:8168-74.

87. Johnson M, Zaretskaya I, Raytselis Y, Merezhuk Y, McGinnis S, Madden TL. NCBI BLAST: a better web interface. Nucleic Acids Res. 2008;36:W5-9

88. Rambaut A. FigTree, a graphical viewer of phylogenetic trees. 2007.

89. Xiong $Y$, Wang $P$, Lan $R$, Ye C, Wang H, Ren J, et al. A novel Escherichia coli 0157:H7 clone causing a major hemolytic uremic syndrome outbreak in China. PLoS One. 2012;7, e36144.

90. Kulasekara BR, Jacobs M, Zhou Y, Wu Z, Sims E, Saenphimmachak C, Rohmer L, Ritchie JM, Radey M, McKevitt M, Freeman TL, Hayden H, Haugen E, Gillett W, Fong C, Chang J, Beskhlebnaya V, Waldor MK, Samadpour M, Whittam TS, Kaul R, Brittnacher M, Miller SI: Analysis of the genome of the Escherichia coli O157:H7. spinach-associated outbreak isolate indicates candidate genes that may enhance virulence. Infect Immun. 2006;2009(77):3713-21

91. Sato T, Shimizu T, Watarai M, Kobayashi M, Kano S, Hamabata T, et al. Distinctiveness of the genomic sequence of Shiga toxin 2-converting phage isolated from Escherichia coli 0157:H7 Okayama strain as compared to other Shiga toxin 2-converting phages. Gene. 2003;309:35-48.

92. Sato T, Shimizu T, Watarai M, Kobayashi M, Kano S, Hamabata T, et al. Genome analysis of a novel Shiga toxin 1 (Stx1)-converting phage which is closely related to Stx2-converting phages but not to other Stx1-converting phages. J Bacteriol. 2003;185:3966-71.

93. Su LK, Lu CP, Wang Y, Cao DM, Sun JH, Yan YX. Lysogenic infection of a Shiga toxin 2-converting bacteriophage changes host gene expression, enhances host acid resistance and motility. Mol Biol. 2010;44:60-73.

\section{Submit your next manuscript to BioMed Central and take full advantage of:}

- Convenient online submission

- Thorough peer review

- No space constraints or color figure charges

- Immediate publication on acceptance

- Inclusion in PubMed, CAS, Scopus and Google Scholar

- Research which is freely available for redistribution 